\title{
METHYL BROMIDE POISONING
}

\section{AN ACCOUNT OF FOUR RECENT CASES MET WITH IN ONE OF H.M. SHIPS}

\author{
BY \\ C. ASTLEY ClARKE, C. G. ROWORTH and H. E. HOLLING
}

From a Royal Naval Auxiliary Hospital

The increase in the use of methyl bromide in the present war for its fire-extinguishing properties has made the problem of poisoning by this chemical of interest in the Services.

\section{Physical Properties and Uses of Methyl Bromide}

Methyl bromide is a gas at ordinary temperatures. It is readily liquefied at $0^{\circ} \mathrm{C}$. to a clear, colourless and extremely volatile liquid, boiling at $4.5^{\circ} \mathrm{C}$. $\left(40 \cdot 1^{\circ} \mathrm{F}\right.$.). It has a melting point of $-93^{\circ} \mathrm{C}$. When diluted, the gas is almost odourless, but in higher concentrations it has a musty, acrid smell. In cases of poisoning in man a sweetish odour in the breath has sometimes been noticed; where death has occurred the same odour has been noticed in the internal organs at autopsy.

Methyl bromide is used in the chemical industry as a methylating agent. It is also used for refrigeration purposes, as a fumigant in the control of rodents and fleas and in the disinfestation of stored grains and foodstuffs. The quantity used for fumigating food is so small, however, that poisoning from swallowing the vapour is very unlikely to occur. As a fire-extinguisher, methyl bromide acts by reason of its great density, being about three times as heavy as air; a blanket of vapour forms over the fire, and oxygen is thereby excluded. One pound of the liquid will generate $3.7 \mathrm{cu}$. $\mathrm{ft}$. of the gas at N.T.P. The vapour has no action on mustard gas detector paint, and the Service respirator affords but little protection although in an emergency it may be used for a period of not more than five minutes. It must be remembered, however, that in dealing with a fierce fire which is incompletely extinguished by methyl bromide, thermal decomposition products (particularly bromine) may be liberated. These, by their smell, would give warning to unprotected personnel, but a false sense of security might be induced in those wearing respirators, resulting in inhalation of the almost odourless methyl bromide.

\section{Occurrence of Poisoning}

Methyl bromide poisoning was first reported in 1901 by Jaquet, and the majority of cases up to the beginning of the present war occurred in workmen who had been engaged in the manufacture of the compound. Up to 1940 , only 42 cases had been reported in the literature, mostly in Germany. Of these 12 were fatal, 23 recovered and in 7 the information was incomplete. Since 1939, cases have been more numerous, and in the Royal Navy 22 have been reported, with 6 fatalities.

\section{Toxicity}

Methyl bromide is more toxic than ethyl bromide and both are more toxic than methyl and ethyl chloride. Delayed action, which is common to the whole group, is most marked with methyl bromide.

Information concerning the concentration of methyl bromide at which toxic symptoms occur in man is scanty. The figures are also liable to be misleading, owing to the density of the gas, which results in its sinking to the lowest level of a compartment. Factors such as ventilation and the breathing-level of those exposed to the poison may result in different amounts of the gas being absorbed by persons in the same affected compartment. The following facts, however, have been gathered from the literature, and it will be seen that similar orders of concentration have approximately the same toxicity in both animals and man.

Effects on Animals (Rats). (1) 11,000 parts per million can be survived for three minutes only. (2) 2200 parts per million can be survived for 24 minutes. (3) 440 parts per million are fatal after 6 hours exposure. (4) 220 parts per million are lethal after 22 hours exposure, but animals can survive this concentration if removed from the chamber after 8 hours. (5) 92 parts per million are survived for 22 hours by all the animals.

Symptoms are said to occur earlier if a gas flame is present in the chamber; it has been surmised that this is due to the oxidation of the compound to a more poisonous product.

Repeated exposures in animals showed that a quarter of the maximum concentration tolerated for a single 8-hour exposure could be tolerated daily for 6 months without demonstrable effects. This indicates that the rat can either destroy or excrete 
non-lethal quantities of methyl bromide without harmful effects.

Effects on Man. (1) 10,000 parts per million of methyl bromide vapour are fatal if inhaled for more than a few minutes. (2) Miller (1943) reports the case of a man moribund after an escape of methyl bromide which could have given an overall concentration of 8000 parts per million in the refrigerator car where he was found. (3) 220 parts per million can be endured by man for several hours without serious effects (4) 50 parts per million may produce mild symptoms in man after 8 hours' exposure. (5) Watrous (1942) reports that of 90 persons working in the filling and sealing room of a methyl bromide factory, 30 developed minor symptoms at some time during a two-week exposure to a concentration of often about 35 p.p.m. The estimation in these cases was done by the 'Frigidaire' leak detector. This is a small blow torch, using methyl alcohol for fuel and equipped with a copper combustion tube into which air is drawn by a tubular duct. The presence of any halide in the air causes the almost colourless flame to assume various shades of green or blue, roughly proportional in intensity to the vapour concentration. The lower limit of sensitivity to the apparatus is 35 p.p.m. of methyl bromide.

From the above it will be realized that for practical purposes any methyl bromide present in the atmosphere must be regarded as a source of great danger.

\section{Symptomatology}

(a) Symptoms resulting from High Concentrations of the Vapour. At a concentration of the order of 1 per cent. (by volume) methyl bromide not only has the musty acrid smell already mentioned but is also markedly irritant to the upper respiratory tract. Consequently, provided escape is possible, the length of exposure is likely to be short. Following a brief exposure to such a concentration of the gas, victims may complain of headache, smarting of the eyes, cough, loss of appetite, abdominal discomfort, and numbness of the feet. Most of these symptoms pass off in a few days, but peripheral paraesthesiae have been noticed as a residual symptom for as long as $3 \frac{1}{2}$ months. Where men have been overcome by the fumes or unable to escape, death may take place within 48 hours from pulmonary oedema. Irritation of the central nervous system is not a feature of exposure to very high concentrations; death presumably results from pulmonary oedema before nervous symptoms develop, or because the victim avoids the irritant gas before he has had time to absorb much of it.

(b) Symptoms resulting from Lower Concentrations of the Vapour. Here exposure is likely to be more prolonged, as the presence of the vapour is not appreciated. Mild symptoms such as malaise, headache, smarting of the eyes and nausea which may occur soon after an incident are often attributed to dietary indiscretion, over-smoking, bad ventilafion or an attack of influenza. After a period of some hours, usually two to sixteen, but sometimes longer, delayed symptoms make their appearance, and these are often the first reason for seeking medical aid. Characteristic of these delayed symptoms are visual disturbances-difficulty in focussing objects and occasionally actual amblyopia -symptoms of alcoholism, apathy, drowsiness, paresis of the lower extremities and epileptiform attacks. When these last occur the prognosis is extremely bad, and the literature only reports one case which recovered after fits had supervened. Complete recovery may be a matter of weeks or months, visual symptoms often persisting the longest. Convalescence may be characterized by depression, irritability, lassitude, sleeplessness and inability to concentrate. These psychological disturbances may even persist for years, but there is some evidence to show that when they do the subject has previously been of unstable nervous temperament.

(c) Symptoms resulting from Minimal Concentrations of Vapour. Following prolonged exposure to very low concentrations (of the order of 35 p.p.m.), the characteristic fits do not occur. Under these conditions the commonest complaints are anorexia, nausea, headache and pains in the quadriceps, all of which disappear rapidly when the patient leaves the contaminated area. The same symptomatology may occur in short exposures to somewhat higher concentrations.

(d) Symptoms resulting from Contact with Liquid Methyl Bromide. Liquid methyl bromide on the skin produces burns. It rapidly penetrates clothing, and even boots are not proof against it. Rubber and adhesive tape absorb and retain the chemical, and contact with these may also cause skin lesions. An erythema of the feet and ankles has been reported as occurring within 60 minutes of exposure and some hours later large bulbous blisters appeared in the same areas. In less severe cases a fine papular rash has been described appearing on exposed sites in 7 or more days, and healing in one week after its appearance.

\section{Mode of Action of Methyl Bromide}

Although the exact mode of action of methyl bromide has not been ascertained, the following facts are known :-

(1) Methyl bromide has so far not been recovered from the tissues or body fluids either in man or animals.

(2) After exposure to the vapour of methyl bromide there is a definite increase in the nonvolatile bromide in the blood. Rabbits have a blood bromide of approximately $11 \mathrm{mg}$. per cent. after repeated 8-hour exposures to 60 p.p.m. of methyl bromide, and at this level they show functional responses to the poison. Control animals gave a figure of $1 \mathrm{mg}$. per cent. Feeding inorganic bromide in amounts sufficient to maintain the blood bromide level far above that in animals exposed to methyl bromide failed to produce any comparable results. In man the non-volatile bromide in the 
blood is also increased, in two fatal cases of poisoning, the figures being 9.2 and $8.3 \mathrm{mg}$. per cent. respectively (normal $0-1.5 \mathrm{mg}$. per cent.).

(3) Rabbits exposed to methyl alcohol vapour in concentrations equivalent to or greater than that which would be obtained by the hydrolysis of intoxicating concentrations of methyl bromide showed no functional response comparable to methyl bromide poisoning. Again, exposing rabbits to methyl alcohol vapour and feeding them with sodium bromide produced no functional response comparable to the effect of methyl bromide, even with a blood bromide of $90 \mathrm{mg}$. per cent.

(4) Animals recover quickly and completely from repeated sublethal daily exposures and in man a case has been reported where poisoning occurred on five different occasions with complete recovery from each attack. It must be noted, however, that there was an interval of years between each exposure.

The first of the above facts suggests that the methyl bromide molecule is not itself responsible for the clinical picture of ' methyl bromide' poisoning. The second and third points suggest that neither sodium bromide nor methyl alcohol are the responsible factors; nevertheless, since they appear to be the likely hydrolysis products of methyl bromide, suggestions have been brought forward with a view to showing that either the bromine or methyl radicle may be in some way responsible. Thus, Miller and Haggard (1943) have propounded an ingenious theory suggesting that "intra-cellular bromism' is the cause of the toxicity. It is known that bromine ions do not pass readily through a cell membrane, whereas methyl bromide molecules do. The theory is that though some methyl bromide is hydrolysed in the extra-cellular fluid, some of the compound undergoes this process in the cells of the C.N.S., with the result that bromine ions are trapped in the nerve cells. It is supposed that symptoms caused by such intra-cellular bromism would differ from those which follow an overdose of such a salt as sodium bromide. This theory, however, does not explain why the symptoms of methyl chloride intoxication (which cannot be explained on the intra-cellular bromine hypothesis) should be so similar to those of methyl bromide.

Those who ascribe the toxicity of methyl bromide to the 'methyl' radicle point out certain similarities between methyl bromide and methyl alcohol poisoning. The only common feature worth considering in this connection is that in a very few cases scotomata and even amblyopia have been reported after exposure to methyl bromide; where these have occurred the similarity to the blindness resulting from methyl alcoholism has been seized upon. If the toxicity of methyl bromide were in fact due to methyl alcohol, one would expect amblyopia to be a frequent finding, yet there has been no suggestion of it in any of the cases which have come to our notice. Moreover, fits which are highly characteristic of methyl bromide, do not occur after methyl alcohol poisoning; neither is there any resemblance between methyl bromide poisoning and that which results from the oxidation products of methyl alcohol-formic acid and formaldehyde.

The fourth point suggests that methyl bromide has no cumulative action and that acquired sensitivity to it is unlikely.

From the above observations it will be seen that the problem of methyl bromide poisoning remains unsolved, but it appears likely that some decomposition product (at present unknown) is the responsible factor.

\section{Present Series of Cases}

Four officers, three males and one female, were accidentally exposed to an unknown concentration of the vapour of methyl bromide for varying lengths of time, as a result of the leakage of the fire-fighting apparatus in one of H.M. ships.

In the craft in which the accident happened the cylinders of methyl bromide are placed in one part of the ship and each is connected by piping to the compartments in which a fire might occur. The cylinders have the usual collar and screw connection to be found in the normal commercial gas cylinders but they have no stop-cocks, the gas being contained by a metal diaphragm which is seated behind the collar-nut. Inside the first part of the pipe to which these cylinders are attached is a metal pin worked by an external lever; when the latter is moved the pin ascends, perforates the diaphragm, and releases the gas into the system. The incident in question was due to the accidental movement of one of these levers, which allowed the gas to escape into a compartment beside the wardroom. From there it leaked into the wardroom causing the effects described below.

At 20.15 on January 8th, 1944, two officers A and B, both aged 20 years, were admitted to hospital after an urgent ambulance call. A was unconscious and having violent fits. $\mathbf{B}$ was conscious, and although somewhat drowsy was able to give the following history. He and the other officer, on turning out on deck after breakfast, both thought they had influenza. They were working together all the forenoon and going into the wardroom before lunch, at about midday, felt quite well. They lunched at 13.00 , and enjoyed it, with the exception of some onions, which they said they thought tasted queer. After lunch, a third officer, $C$, came into the wardroom with a female officer, $\mathrm{D}$, and they all four had coffee there. At 14.00 A and $B$ turned out on deck to continue working and noticed that their eyes were smarting. About 15.00 they both began to feel ill and went below to lie down in the wardroom. Nothing further was seen of them until 18.00, when they both vomited, ascribing their condition to the onions. Vomiting continued, and when $\mathrm{A}$ began to lose consciousness the crew became worried and requested medical aid.

B's story on arrival in the hospital was so extraordinary that a medical officer was immediately sent to the craft to make further investigations. He arrived at $\mathbf{2 0 . 3 0}$ hours and the inquiry began at this time in the wardroom. The following facts were 
elicited:-(1) The lunch, onions included, had been shared by all on board; the rest of the crew had enjoyed it and none had been taken ill. (2) The food for A and B had been brought forward in a safari-tin (a large thermos) by the officers' steward, who was under punishment. The remains of the food had been thrown overboard by the latter. When inspected, the glass inside the safari-tin was found to have been smashed to atoms and the steward could give no account of how this had been done. (3) The fire-fighting apparatus was stated by the rating in charge to be in order. (It must be remembered that weighing is the only possible test for the fullness of the cylinders, and this could not be done with them in situ.) (4) At 21.00 case C arrived on board in response to a request to attend the inquiry. It was with the greatest difficulty that he had been persuaded to leave the nearby hotel, where he had had dinner with the female officer (case D). His eyes were bloodshot and he was in a most perverse frame of mind. He was completely unhelpful and appeared to care little for the fate of the other two officers, although it was pointed out to him that they were desperately ill and that any information he could give might help in the diagnosis and treatment. He appeared anxious to leave the craft and was eventually allowed to do so in order to take the female officer home. He was instructed to go to the hospital after having done this.

The inquiry then ended; a certain amount of suspicion had been thrown on the steward who had taken the food to the two officers, but the theory of food poisoning seemed a little far-fetched. The unusual behaviour of case $\mathrm{C}$ was unexplained and it was only afterwards that his symptoms were recognized as being due to methyl bromide poisoning.

The medical officer who had conducted the investigation, and who had been in the wardroom for about an hour, now returned to the hospital. On arrival there he noticed a soreness in his eyes. He then realized that the atmosphere of the wardroom must have been responsible, and, as it was known that methyl bromide was contained in the fire-fighting apparatus, the scanty available literature on the subject of poisoning by the vapour was immediately referred to.

Information was then received that case $\mathrm{C}$ was very ill in his ship, having failed to report at the hospital. He was immediately admitted. Inquiries were also made as to the state of case $D$, who had returned to her hostel. It was discovered that she had vomited since her arrival there and she, too, was admitted to hospital. Orders were also given for the crew to be removed from the craft. Later, one of them vomited slightly; he was admitted for the night but had no further symptoms.

\section{Case Records}

Case A, male, aged 20 (20.15/8). Admitted to hospital deeply unconscious. Eyes bloodshot, heart and lungs normal, colour good, pulse 120 . Normal pressure. History of having had several fits.

20.30. Severe epileptiform convulsion, with very short tonic stage. This fit, which was typical of all, both in cases $A$ and $B$, lasted from 3 to 4 minutes; in the clonic stage the flexor muscles over the whole body were contracting strongly with a period of $80-90$ a minute. These contractions appeared to become stronger with each attempt at inspiration, when the intercostal muscles joined in and, interfering with the respiratory process, the patient became more cyanosed as the fit progressed. At the end of the convulsion the contraction ceased quite suddenly; the breathing became normal, the colour returned and the pulse dropped to 120. The convulsions returned at 15 -minute intervals, and between them the patient was quiet, with flaccio muscles. The tendon reflexes were normal, plantar responses flexor and the pupils reacted to light. There was, however, no return to consciousness and the corneal reflexes were absent.

21.30. During the next hour the fits were slightly more frequent but the patient's general condition remained good. A specimen of urine was tested and was found normal, but only a few cubic centimetres were passed and he had certainly not emptied his bladder for the previous two hours.

22.30. For the next hour the fits were more frequent and less violent, and it was hoped that this was a sign that he was getting better.

23.30. The convulsions now began to last for longer periods and the intervals became shorter, with consequent interference with respiration, and loss of colour. The pulse rate began to rise, and efforts were made to try and control the contractions. Omnopon gr. $\frac{1}{2}$ was given at 22.30 and at 23.45 ; this was followed by 15 c.c. of pentothal sodium intravenously. The patient immediately became quiet and the respirations regular although shallow. The pulse returned to 120 and the colour became good. The effect of the drugs, however, did not last for more than 50 minutes.

$00.30 / 9$. A continuous pentothal intravenous drip was set up, but it very early became obvious that it was impossible to control the contractions without anaesthetising the patient so deeply as to depress the respirations to danger point. The colour became very poor and the pulse irregular, so the drip was stopped.

01.00. The Boyle's anaesthetic apparatus was set up with the mask strapped to the patient's face and continuous oxygen and chloroform given. The patient's condition began to improve at once, and within half an hour it became possible to reduce the contractions almost to vanishing point whilst maintaining fairly good respirations; these, with the increased oxygen tension, improved his colour and the pulse again dropped to 120 per minute.

At 01.30 further gr. $\frac{1}{2}$. omnopon was given. Oxygen and chloroform were continued until 06.00 .

06.00 The patient's condition now appeared to have improved. For the previous hour the contractions had been almost absent, and very little chloroform had been used. The pulse, while it was still generally in the region of 120 per minute had been as low as 110 on several occasions. His colour was good and the chest dry. It was therefore decided to stop the oxygen and chloroform and this was done at 06.00 .

06.10. Within a few minutes of removing the mask there was a very severe convulsion and the colour failed at once. The pulse became uncountable. Two c.c. of coramine were given and the mask replaced. The contractions were again controlled but he remained cyanosed. Some blood was removed for examination and, owing to a mistake in reading the apparatus, a high percentage of methaemoglobin (60 per cent.) was reported. On account of this a transfusion of 500 c.c. whole blood was given, but this had no effect.

07.00. The contractions now became more difficult to control and there was the same difficulty as was experienced with pentothal in the beginning-that is, in order to control the contractions the respirations had to be depressed to danger point.

09.00. The patient's general condition began to deteriorate rapidly, and it was obvious that death would not be long delayed. The pulse became irregular and 
difficult to feel. Oedema of the lungs supervened and it was apparent that the heart was failing. Death finally took place at $11.25 / 9$.

Autopsy. Performed 10.30 on January 10th (about 24 hours after death). The body was that of a wellnourished male of about 20 years of age. . No signs of external injury. There was marked post-mortem lividity. The conjunctivae were inflamed and there were peri-orbital ecchymoses present on each side. Tongue furred. Throat normal. No abnormal odour noted on section of the cadaver. The trachea contained much blood-stained mucus and there was three-quarters of a pint of blood-stained fluid in each pleural cavity. The lungs were very oedematous and much bloodstained fluid could be expressed from the smaller bronchi. No evidence of consolidation and the lungs contained air. Sub-pleural haemorrhages were marked, coalescing at the bases to form purpuric sheets. Localized emphysema was present along the anterior margin of the left lung. Bronchial glands normal. The heart was normal except for right-sided dilatation, the tricuspid valve admitting the tips of four fingers. No sub-pericardial haemorrhages. The liver, spleen and kidneys appeared normal. The brain showed marked congestion with numerous haemorrhages scattered throughout the brain, particularly on the right side. Portions of brain, heart, lungs, liver, kidneys and spleen were removed for pathological examination and later were reported on as follows :-

Kidney: Glomeruli show dilatation of the capillary loops. All tubules show degenerative changes but these are most severe in the convoluted tubules in which they have gone on to virtual necrosis. The interstitial tissue shows marked vascular congestion. A part of the above changes is due to autolysis but in addition there is a severe degree of toxic damage. Liver: shows congestion, cloudy swelling and slight fatty change. Spleen and myocardium: no apparent lesions. Lungs: show intense congestion with intra-alveolar haemorrhage. Brain: corpus striatum. There is congestion of the smaller vessels and localized peri-vascular haemorrhages around a few of them. No parenchymatous lesions made out. Cerebral cortex: similar to above. Medulla: similar to corpus striatum. Pons: no apparent lesion.

Case B, male, aged $20(20.15 / 8)$. Admitted to hospital. Drowsy, but able to give the history already quoted. Eyes bloodshot. Clinical examination showed no abnormality in the heart, lungs or central nervous system. Pulse 96. The patient fell into what appeared to be a normal sleep, from which he could be roused.

21.00. Severe convulsion of the same type as case A. Omnopon gr. $\frac{1}{2}$ given. Following the fit he became quiet and remained asleep until 22.30 .

22.30. Severe convulsion lasting 6 minutes. Condition following this fit was good. Pulse 100.

23.34. Severe convulsion, during which the pulse was almost uncountable. Coramine 1 c.c. Omnopon gr. $\frac{1}{2}$.

23.45. Convulsion, following which the pulse returned to 118 . He became quiet again and the pulse slowly returned to 100 .

$01.00 / 9$. Severe convulsion, morphia gr. $\frac{1}{4}$ given. Following this the patient became quiet, and he remained so until 03.00, when he woke up and asked for something to drink; this was given to him and he went off to sleep again.

09.00. Condition unchanged; pulse 110, colour good. $\mathrm{He}$ had not become conscious again but he was not disturbed and it was hoped that he was improving. He remained the same until 11.30.

11.30. Further severe fit lasting 6 minutes, followed rapidly by another. He passed into a state of continuous clonic contractions and the Boyle's apparatus was set up as in case A. The contractions were never completely controlled, however, and by 12.30 his condition was desperate.

12.30. Pulse uncountable and very irregular. Oedema of lungs. He died at $15.15 / 9$.

No autopsy was performed.
Case C, male, aged 30. The previous behaviour of this patient has already been described.

23.15/8. Admitted to hospital. He complained of very severe pain in the eyes and was rolling about in the bed. The eyes were bloodshot and watering profusely; the lids were puffy and tender. He could answer questions but was not completely rational. Examination of the heart, lungs and central nervous system showed no abnormality. He was given morphia gr. $\frac{1}{3}$ which controlled the restlessness, and on the following day had much improved.

$10.30 / 9$. The patient was now completely rational and had a proper appreciation of the happenings of the previous day; he reacted normally to the information about the other officers.

Examination showed slight bilateral conjunctivitis and oedema of both upper lids. No rash; tongue furred; throat injected; heart normal; blood pressure 136/92. C.N.S.: pupils normal, knee and ankle jerks present but weak; plantar responses flexor. Fundi normal, no haemorrhages seen. Urine normal.

Progress. The patient was kept in bed under observation and in general made a good recovery. He was allowed up for a short time as from January $17 \mathrm{th}$, when difficulty in focussing was his only complaint. On this day his urine was reported to contain granular casts, but they were never discovered subsequently. His convalescence was retarded by a moderate degree of mental depression and he was not found fit for duty until March 20th, 1944.

Case D, female, aged 27. This patient was affected far less than any of the preceding. She had noticed, at about 20.30 in the wardroom, that her eyes were pricking and that her throat felt dry. She returned to her hostel, drank a pint of milk and vomited once. On admission to hospital on the night of January 8th her eyes were seen to be very slightly injected and she complained of a little dizziness. She had no serious subsequent symptoms. She was kept in hospital for one night, and the following day physical examination was entirely negative, but she complained of a productive cough. This persisted for two days, when she coughed up a lot of thick yellow phlegm which she stated contained small lumps of blood. She only reported this later. She was allowed to leave the hospital and when seen again about a month later, after sick leave, she had completely recovered and was allowed to return to duty.

Conclusive evidence that methyl bromide had been in fact the cause of the symptoms was forthcoming the day after the incident when one of the cylinders was weighed and found to be empty.

\section{Discussion}

Diagnosis. The cases outline above show the typical symptoms and course of methyl bromide poisoning in varying degrees of severity. In retrospect, the diagnosis is easy, but unless knowledge of the toxicity of methyl bromide is more widely circulated there is danger of the poison not even suggesting itself as a possible diagnosis. It cannot be too widely known that where a number of simultaneous cases of poisoning occur in a small ship, the fire-fighting apparatus should immediately be investigated.

Similar symptoms might be produced by carbon monoxide poisoning, but the colour of the patient and the fact that there are no delayed effects in this condition should distinguish it from methyl bromide poisoning. In the present series, owing to the circumstances associated with the incident, strychnine poisoning was at first suspected, and it was not until the investigating medical officer noticed that 
his own eyes were smarting that it was realized that the poison had been inhaled and not taken internally. Apart from the prodromal symptoms, strychnine poisoning also differs in that the convulsions follow one another at very quick intervals and that the abdominal muscles show board-like rigidity.

In isolated cases where the symptoms are mild, alcoholism might be suspected; where severe, status epilepticus or fulminating cerebro-spinal meningitis might be erroneously diagnosed.

Prognosis. The severity of the symptoms and the likelihood of death from methyl bromide poisoning depends, as has already been stated, on the concentration of the vapour and the length of time of exposure. In the present series of cases the latter is not known very accurately, but in the two fatal cases, A and B, it was about five hours, in case $\mathrm{C}$ about three hours and in case $\mathrm{D}$ about two hours. The concentration to which they were subjected is not known.

It will be seen that the fatal cases were exposed for approximately twice as long as the survivors. Animal experiments performed to determine the length of time for a given concentration following which there was 100 per cent. survival showed that when this time was doubled or slightly more than doubled, all the animals died. This point might conceivably be useful in deciding priority treatment in man. Thus, if a series of cases occurred one or more of which had been fatal in a known time, it would be reasonable to infer that survivors who had only been exposed to the vapour for half as long or less would be unlikely to succumb, and attention could be given to those who had had a greater length of time in contact with the vapour. The point is not so abstract as it may at first appear. The difficulty with any given case is to know whether or not fits are likely to supervene. If they do death is almost certain. In the present series of cases $B$ by no means appeared desperately ill on admission to hospital, but the fact that he had been in the wardroom for the same length of time as A (who was having fits) under similar conditions could have enabled a bad prognosis to have been given.

The rise in the blood bromide may also prove to be of assistance in assessing the prognosis, but there is as yet insufficient data on this point and, as will be seen below, the difference in reading between the fatal and non-fatal cases is small. It seems probable that this investigation may be more useful in deciding whether or not methyl bromide poisoning has occurred at all. Thus, men working in a ship but sleeping ashore who report at the sick bay complaining of headache and loss of appetite may ascribe these symptoms to a leak in the fireextinguishing apparatus. Considerable loss of efficiency is likely to result unless there is some reliable way of making a quick diagnosis. The ideal method is to test for the vapour in the ship concerned (by some such means as the Frigidaire leak-detector). This, however, may not always be practicable and it is possible that blood bromide investigations may be of assistance in arriving at the correct conclusion. The practical drawback is that the analysis is somewhat complicated and, unless expert laboratory facilities are available, there is likely to be considerable delay.

Chemical Analyses. The chemical analyses * in the present series are given below :-

Case $A$.

Day of incident non-volatile bromide content

$\begin{array}{cccc}\text { of blood } \ldots & \ldots & \ldots & 9.2 \mathrm{mg} .\end{array}$

$" \quad$, of urine $\ddot{0} \quad \ldots$ content non-volatile bromide content

, of stomach contents $\quad . \quad 2.3 \mathrm{mg}$.

Case $B$.

Day of incident non-volatile bromide content $\begin{array}{lllll}\text { of blood .. } & . & . & 8.3 \mathrm{mg}\end{array}$

Case $C$.

Day of incident non-volatile bromide content of blood .. ... ..

12 days after incident.

39 days after incident.

Case D. of blood bromide content of blood . . . . . . $6.9 \mathrm{mg}$. $6.9 \mathrm{mg}$.

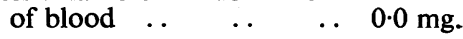

Day of incident non-volatile bromide content 12 days after $\quad \begin{gathered}\text { of blood } \\ \text { non-volatile bromide content }\end{gathered}$ incident

31 days after incident. 41 days after incident. non-volatile bromide content of blood .. $\quad . . \quad \ldots \quad 0.8 \mathrm{mg}$ non-volatile bromide content

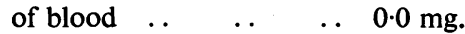

$6.9 \mathrm{mg}$ $6.9 \mathrm{mg}$. $0.8 \mathrm{mg}$

From the above it will be noted: (1) That the severity of the symptoms in cases $A, B$ and $C$ was roughly paralleled by the blood bromide levels; (2) that there was only a difference of $2.3 \mathrm{mg}$. per cent. and $1.4 \mathrm{mg}$. per cent. respectively between case $A$ and $B$, who died, and case $C$ who survived; (3) that in the survivors the blood bromide level took more than 12 days to reach a normal level.

Further research is necessary before it is known whether any of the above findings are significant, because: (1) the readings as a whole are very low; (2) the normal blood bromide figure is up to $1.5 \mathrm{mg}$. per cent.; (3) the rate of excretion of inorganic bromide at low levels has been found to be very slow in cases of potassium bromide poisoning; (4) in case $D$ there was no parallelism between the blood bromide level and the severity of the symptoms.

This raises the question of individual susceptibility to methyl bromide. Striking examples are often referred to in the literature where two people have apparently been exposed to similar poisonous concentrations of the vapour, one succumbing and the other showing no symptoms. As has already been mentioned, there is great difficulty in assessing the actual concentration to which any given individual has in fact been exposed. Nevertheless, in case $\mathrm{D}$ it must either be assumed that a raised blood bromide level was of no significance or that she possessed a degree of tolerance which was not present in the three male cases.

* Determined by the processes of Dudley $e t$ al. (1940) and confirmed by the method of Friedman (1942). The references show that the analysis determines the level of the non-volatile bromide in the fluids concerned and not, as was first thought, the actual methy!
bromide content. 
Pathological Findings. The post-mortem examination in case A shows similar findings to those elsewhere in the literature. It is of interest that albuminuria was not present in view of the degenerative changes noted in the kidneys. Glaser states that albuminuria is usual, but it has not been described in any of the cases in the literature to which we have been able to refer. A cerebro-spinal fluid examination was not done in any of our cases, but in other series it has been shown to be normal.

Treatment. No effective treatment has yet been discovered when fits supervene, although in the literature morphia, oxygen, artificial respiration, lumbar puncture, venesection and adrenalin are all mentioned. Although continuous oxygen and chloroform was not successful in either of the fatal cases described in this paper, yet in case A it appeared definitely to prolong life, and it would appear rational to persevere with this treatment continuously up to a period of 24 hours or more if necessary. Chloroform can be given without any exceptional risk to the liver. Statements in the early literature inferring that methyl bromide is a liver poison are probably due to the fact that there was associated carbon tetrachloride poisoning. The post-mortem report in case $\mathrm{A}$ of our series showed minimal liver damage only.

Mild cases of methyl bromide poisoning need no special treatment other than fresh air and rest in bed, for at least 48 hours; a period of at least 2 or 3 weeks convalescence is, however, essential, in view of the frequency with which depression, irritability and other anxiety symptoms may occur.

The moderately severe case of methyl bromide poisoning presents the most difficult problem, as there is always the possibility for 48 hours that fits may occur. On the assumption that it is the ' methyl ' radicle which is responsible for the delayed poisoning effects, substitution therapy with methyl alcohol was suggested, though it has now been worked out that the amount of alcohol required to dissolve the methyl bromide would kill the man.

Skin lesions resulting from liquid methyl bromide heal readily; chlorbutal ointment has been used with good effect to relieve pain.

As almost all recorded cases of methyl bromide poisoning, both before and during this war, have been due to accidental escape of vapour and not as a result of actual fire-fighting, the most hopeful line of treatment lies in prevention, with better supervision of fire-fighting apparatus, and familiarization of personnel with the symptoms of the poison. Further research to produce a less toxic and equally efficient substitute is also indicated. Alternatively, a substance with a warning smell might be put into existing stocks of methyl bromide, though if this were done it would seem advisable to give the product a completely different name, so that no misunderstanding could arise in ships already supplied with the odourless gas. Personnel would also have to be informed that in respirators the warning smell would probably not be noticed.

\section{Summary}

Four cases of methyl bromide poisoning have been described. They occurred as a result of leakage of the fire-fighting apparatus in one of H.M. ships.

\section{Acknowledgments}

Our acknowledgements are due to Dr. C. V. Harrison for the histological reports on the postmortem material, and to Professor W. H. Roberts, M.Sc., F.I.C., for the blood bromide estimations.

Our thanks are due to the Medical DirectorGeneral of the Navy and to Surgeon Rear-Admiral Whelan for permission to publish these cases.

\section{LITERATURE}

Adler-Herzmark, J. (1927). Zbl. Gewerbehyg., 14, 161 Beyne, J., and Goett, M. (1934). Arch. méd. Pharm. nav., 6, 124. Browning, E. (1937). Toxicity of Industrial Organic Solvents. Med. Res. Counc. Rep. No. 80. H.M.S.O. Lond.
P. C., Weaver, T. A., and Camp, E. H. (1941). J. Amer. med. Ass., 117, 1256.

Cade, A., and Mazel, P. (1923). Bull. Mém. Soc. méd. Hôp. Paris, 47, 722 .

Dudley, H. C., Miller, J. W., Neal, P. A., and Sayers, R. R. (1940). Publ. Hith. Rep. Wash., 55, Pt. II, 2251

Duvoir, M. M. et al. (1937). Bull. Mém. Soc. méd. Hôp. Paris, 34, 1540.

Floret, E. (1915). Zbl. Gewerbehyg., 3, 146.

Friedman, M. M. (1942). J. biol. Chem., 144, 519

Glaister, J. (1942). Medical Jurisprudence and Toxicology, Livingstone, Edin., p. 541 .

Glaser, E. (1928)., Disch. Z. ges. gerichtl. Med., 12, 470

?rish, D. D., et al. (1940). J. industr. Hyg., 22, 218.

, (1941). Ibid., 23, 408.

Jaquet, A. (1901). Dtsch. Arch. f. klin. Med., 71, 370.

Medical Manual of Chemical Warfare (1940), 82.

Merritt, W. A., and Brown, A. E. (1941). Proc. Mayo Clin., 16, 666. Miller, J. W. (1943). Arch. Path., 36, 506.

Miller, D. P., and Haggard, H. W. (1943). J. industr. Hyg., 25, 423 Watrous, R. M. (1942). Industr. Med., 11, 575

von Oettingen, W. F. (1937). J. industr. Hyg., 19, 349. 